IZA DP No. 6706

Birth Order and Human Capital Development: Evidence from Ecuador

Monique de Haan

Erik Plug

José Rosero

July 2012 


\title{
Birth Order and Human Capital Development: Evidence from Ecuador
}

\author{
Monique de Haan \\ University of Amsterdam, \\ Tinbergen Institute and TIER \\ Erik Plug \\ University of Amsterdam, \\ Tinbergen Institute, IZA and TIER \\ José Rosero \\ University of Amsterdam \\ and Tinbergen Institute

\section{Discussion Paper No. 6706 \\ July 2012} \\ IZA \\ P.O. Box 7240 \\ 53072 Bonn \\ Germany \\ Phone: +49-228-3894-0 \\ Fax: +49-228-3894-180 \\ E-mail: iza@iza.org
}

\begin{abstract}
Any opinions expressed here are those of the author(s) and not those of IZA. Research published in this series may include views on policy, but the institute itself takes no institutional policy positions.

The Institute for the Study of Labor (IZA) in Bonn is a local and virtual international research center and a place of communication between science, politics and business. IZA is an independent nonprofit organization supported by Deutsche Post Foundation. The center is associated with the University of Bonn and offers a stimulating research environment through its international network, workshops and conferences, data service, project support, research visits and doctoral program. IZA engages in (i) original and internationally competitive research in all fields of labor economics, (ii) development of policy concepts, and (iii) dissemination of research results and concepts to the interested public.
\end{abstract}

IZA Discussion Papers often represent preliminary work and are circulated to encourage discussion. Citation of such a paper should account for its provisional character. A revised version may be available directly from the author. 
IZA Discussion Paper No. 6706

July 2012

\section{ABSTRACT \\ Birth Order and Human Capital Development: Evidence from Ecuador}

In this paper we examine the effect of birth order on human capital development in Ecuador using a large national database together with self-collected survey data. Using family fixed effects models we find significant positive birth order effects; earlier born children stay behind in their human capital development from early childhood to adolescence. Turning to potential mechanisms we find that earlier born children receive less quality time from their mothers than later born children. In addition, they are breastfed shorter. The estimated birth order effects are largest for children in their teens growing up in poor, low educated families.

JEL Classification: D1, I2, J1

Keywords: birth order, human capital development, parental time allocation, Ecuador

Corresponding author:

Erik Plug

Amsterdam School of Economics

University of Amsterdam

Roetersstraat 11

1018 WB Amsterdam

The Netherlands

E-mail: e.j.s.plug@uva.nl

\footnotetext{
* Thanks go to seminar participants in Amsterdam and participants at the Annual Conference of the European Society for Population Economics 2012 in Bern.
} 


\section{Introduction}

In this paper we investigate birth order effects on human capital development of children in Ecuador. Specifically, we estimate the relationship between birth order, preschool cognition and secondary school enrollment using family fixed effects estimation to rule out that observed differences in birth order are driven by family size or any other omitted family factor that is shared among siblings. In addition, we explore possible pathways that predict the birth order patterns we observe; in particular, we look for parental treatment differentials and test whether the amount of time mothers allocate to various types of child care depends on birth order.

We have at our disposal two data sources. The data we use to examine the effect of birth order on child schooling and child labor are taken from the SELBEN database which covers almost all poor families in Ecuador at some point during 2001 and 2006. The data we use to examine the effect of birth order on preschool cognition come from a recent survey we held in Ecuador between 2008 and 2010 among a selective sample of poor families with children eligible for early child development programs. Cognitive test scores were taken from children up to 6 years old. Of relevance to our study, mothers were asked questions about, among others, the amount of time spent with each child on a particular day at particular activities.

In this paper we find that child schooling increases with birth order, while child labor decreases with birth order. These birth order estimates are substantial and insensitive to omitted characteristics that children within families share. Similar birth order patterns are also observed much earlier in life; we find positive effects of birth order on various measures of preschool cognition. When we consider the time mothers spend with their children as possible driver behind these birth order patterns, we find that later born children receive more childcare time than earlier born children. In particular, later born children receive much more cognitive childcare time (which includes playing, drawing, talking and reading stories or books). They are also breastfed longer. Our findings are consistent with models where time investment in children early on in life is important to the further development of human capital (Becker, 1965; Cunha et al., 2006; Almond and Currie, 2011).

Since the birth order results we find are opposite to what is commonly found in the western 
world (Björklund and Salvanes, 2011), we tentatively conclude that the negative relationship between birth order and human capital may not hold in the context of a developing country. We do not provide any causal evidence on why this is, but speculate about related explanations that are more common to developing countries: high poverty rates, low levels of parental education and high teenage pregnancy rates. When we look at preschool cognition, we do not find much when we estimate birth order effects on stratified samples. But when we look at school and work outcomes of children in their teens, we find the largest birth order effects in poor and lower educated families. In fact, birth order effects appear slightly negative for teenage children growing up in richer families, having higher educated parents. Poverty (and the absence thereof) seems to be a likely driver behind the birth order divide between developing and developed countries.

The paper continues as follows. Section 2 provides some empirical and theoretical background on the relationship between birth order, cognitive development and child schooling. Section 3 shortly describes Ecuador and the data we have collected there. After introducing the empirical fixed effects strategy in Section 4, Section 5 presents our main birth order estimates for child cognition, child schooling and child labor. In Section 6 we investigate potential explanations for our positive birth order estimates and finally Section 7 presents conclusions.

\section{Background and related literature}

Birth order is a recurrent theme in social science. One of the first references on this topic is Francis Galton's book English Men of Science, which was published in 1874 (Galton, 1874). In there, Galton collected information on the birth order of some hundred successful scientists, observed many firstborns among them, and tentatively concluded that birth order is important, with children

of higher birth order doing worse. Since then, numerous researchers have examined how birth order influences a child's cognitive development and educational attainment. We will first summarize findings from recent birth order studies in developed and developing countries, before we turn to the contributions of this study. 


\subsection{Birth order studies in developed countries}

One of the most influential and recent birth order studies is Black et al. (2005), which clearly aims at establishing a causal relationship between birth order and educational attainment by estimating a family fixed effects model using large administrative samples on all Norwegians who were aged 16-74 somewhere between 1986 and 2000. Similar to the original Galton study, Black, Devereux and Salvanes find that later born children do significantly worse in school. Since then, many researchers have examined comparable birth order relationships using similar family fixed effects techniques with large (and often administrative) samples. Most of these birth order studies confirm that higher birth order hinders cognitive development and reduces educational attainment (Conley and Glauber, 2006; Gary-Bobo et al., 2006; Kantarevic and Mechoulan, 2006; Kristensen and Bjerkedal, 2007; Booth and Kee, 2009; Black et al., 2005; De Haan, 2010).

There are several theories about the economic, psychological and biological causes of negative birth order effects (see Blake, 1989). These theories typically relate changes in childhood conditions to changes in child cognition and schooling. We discuss three such theories, with different sources of childhood variation. First, childhood conditions may vary with family resources (including time and financial resources). If early child investments are important (Cunha et al., 2006; Almond and Currie, 2011), we expect negative birth order effects because earlier born children do not share the family resources with younger siblings, at least not for some time. Second, childhood conditions may depend on the child's intellectual environment. If family intellectual environment can be proxied by the average age of parents and children within a family (Zajonc, 1976), we should find a negative birth order effect because later born children are born into a less favorable family intellectual environment than their earlier born siblings. And thirdly, differences in childhood conditions may have biological or prenatal origins. ${ }^{1}$

While these theories predict negative birth order effects, there is hardly any empirical work

\footnotetext{
${ }^{1}$ Later born children, for example, may face higher prenatal environmental risks because of increased levels of maternal antibody. If maternal antibody attacks the development of their fetal brain (Gualtiery and Hicks, 1985), we expect negative birth order effects. In addition, children born to older parents may also have a weaker genetic make up if egg and sperm quality decline with parental age (Kidd et al., 2001).
} 
testing these theories separately. What complicates matters, as Black et al. (2005) argue, is the difficulty to distinguish between different theories without additional information. There are a few exceptions. Price (2008) investigates whether children of different birth order are treated differently in terms of the time parents spent with them. With data taken from the American Time Use Survey, he observes that first born children receive significantly more quality time from their parents than second born children of the same age from a similar family. De Haan (2010) tackles a related question, asks whether parents treat earlier born children differently than later born children, but looks at financial resources instead of time resources. With information taken from the Wisconsin Longitudinal Study on whether children received any money from their parents, she shows that children of different birth order are indeed raised differently with parents spending significantly less money on later born children. Both these findings are consistent with a resource dilution story, or a modified version thereof; that is, earlier born children do better in school because they receive a larger share of parental resources both in terms of time and money.

\subsection{Birth order studies in developing countries}

While there is ample evidence in developed countries that children of higher birth order tend to do worse in many dimensions, we know fairly little about the effects of birth order on child schooling in developing countries. Empirical birth order studies with a causal focus are scarce. Interestingly, the few convincing empirical studies that are around find a reversed pattern; that is, children of higher birth order stay in school longer and participate less in child labor (Ejrnaes and Pörtner, 2004; Edmonds, 2006; Emerson and Souza, 2008; Tenikue and Verheyden, 2010).

There are several reasons to believe that birth order patterns in developing countries differ in important ways from birth order patterns in developed countries. A large share of children in developing countries grow up in poor, low educated families. Financial constraints and lack of resources, for example, may drive parents to send their children out to work (Basu and Van, 1998). Since ear-

lier born children are, at a given point in time, older and therefore more productive than their later born siblings, they are probably most likely to be send out to work. If the earnings of earlier born 
children then contribute to family resources that allow later born children to further develop their human capital and to go to school, we expect positive birth order effects on child schooling and negative birth order effects on child labor in poor, low educated families (Tenikue and Verheyden, 2010). Developing countries are also characterized by a high rate of teenage motherhood. Teenage mothers often expose their (unborn) children to a more harmful prenatal environment because of poorer prenatal care; this effect is typically found over and above the adverse effect of an impoverished background (Francesconi, 2008). But mothers, including teenage mothers, may gain maternal experience and turn into better mothers offering a more nurturing environment for their later born children. If a mother's ability to provide a better environment for children to do well in school indeed depends on her age and experience, we expect positive birth order effects. As we already mentioned, there is little work done testing these explanations empirically.

\subsection{Our contributions}

Two messages emerge from the causal birth order literature. The first message is that birth order effects are systematically different in developed and developing countries. The second message is that there is little empirical work done on what is causing these birth order effects, let alone work on what is causing the birth order divide between developed and developing countries.

In this study we have set ourselves the goal to better understand why this is and explore the effect of birth order on human capital development in the context of a developing country. Apart from estimating the effect of birth order on child schooling, and relatedly, child labor in Ecuador for the very first time, our study contributes to the birth order literature in two ways. First, we examine to what extent birth order affects child cognition, measured when children are in their preschool years. If birth order effects are persistent, we should see that birth order effects in early childhood carry over into adolescent years. Second, we follow Price (2008) and examine to what extent birth order affects the time mothers invest in her children. In contrast to Price, however, we need to explain a birth order effect in the opposite direction; that is, we should find that mothers invest more (and not less) time in later born children than in earlier born children. The relationship 
between birth order, early child cognition and time investments have not been studied previously, at least not in the context of a developing country.

Beyond contributing to the causal birth order literature in economics, our work is part of a rapidly developing literature on the long term effects of childhood learning. Much of this work discusses how skills beget skills, where skills obtained early on in life make it easier to acquire skills in later years; see Cunha et al. (2006) and Almond and Currie (2011) for discussions. Our results indicate that the positive birth order effects we observe in early childhood persist over time.

We also contribute to the growing empirical literature on time investment in children. Other recent empirical research highlights the importance of time investment in children to the development of human capital. Using data from the American Time Use Survey, Guryan et al. (2008) find that more schooled parents spend more time with their children, which is consistent with more schooled parents having more schooled children. In the birth order domain, we already mentioned the work of Price (2008) who finds that parents spend significantly less time on later born children. Also in developing countries, there is work connecting parental time investments to child schooling outcomes. Using data from the Indian Time Use Survey, Barcellos et al. (2012) find that girls receive less childcare time than boys, pointing out that women in developing countries fare worse than men in many dimensions, including schooling.

Finally, we contribute by investigating how breastfeeding varies with birth order. In work related to ours, Jayachandran and Kuziemko (2011) study breastfeeding as a form of contraceptive. If mothers continue to have children (and thus limit breastfeeding) until the preferred number of children is reached, they predict that last born children are breastfed more. Among Indian women, they find supportive evidence. If there are cognitive benefits of breastfeeding, as suggested by Rees and Sabia (2009), the observation that later born children are breastfed more corresponds to the positive birth order effects observed in developing countries. 


\section{Context and data}

Ecuador is a lower-middle income country with 13 million inhabitants. Poverty and inequality are considered to be great concerns. In 2006, around 38 percent of the Ecuadorian population were considered poor as their per capita consumption was below the national poverty line. The income distribution is highly unequal; while the bottom 40 percent of the population accounts for 15 percent of national consumption, the richest 20 percent accounts for about half of national consumption (SIISE, 2010). In Ecuador the fertility rate is about 3.3 births per woman and 26 percent of the mothers are below the age of 19 at first birth.

Children in Ecuador start school at age 6 and education is compulsory until age 14. Primary education consists of six years followed by six years of secondary education of which the first three years are compulsory. In primary education almost all children are enrolled in school. The secondary enrollment rate is much lower with a sharp drop at the transition from compulsory to non-compulsory education.

Consistent with other developing countries, child labor is common in Ecuador; in 200911.3 percent of all children between 12 and 18 years old worked instead of going to school. Child labor is even more prominent among children above the compulsory schooling age; about 17.1 percent of children between 15 and 18 years old participate in the labor market instead of attending classes at school (Ecuadorian Labor Survey, 2009). ${ }^{2}$

The data used in the empirical analysis comes from two different sources. To examine the relationship between birth order and late childhood outcomes we use data from the Ecuadorian System of Selection of Beneficiaries (SELBEN). To investigate the extent to which birth order influences early childhood outcomes, not contained in SELBEN, we rely on self-collected data from the Ecuadorian Study of Early Childhood Development Programs (ENEVIN). These two data sets are comparable in important dimensions and described in more detail below.

\footnotetext{
${ }^{2}$ These figures exclude children that both work and go to school.
} 


\subsection{SELBEN}

SELBEN contains survey information on socioeconomic background, labor supply, school enrollment, family relations and demographic characteristics of all family members living in geographical areas previously selected by a poverty map. It covers around $90 \%$ of the rural and urban areas with a high incidence of poverty. The survey information is used to determine the eligibility of families for several government programs aimed at helping the poor. Survey data is collected in 2001-2006 with detailed information about the fertility history of all women between 12 and 49 years old.

The data set contains information on 622,723 families with $1,012,756$ children of secondary school age (between 12 and 18 years old). Since we exploit within-family variation in the fixed effects models we restrict the sample to include only families with a minimum of two children. In addition we restrict the sample to families with a maximum of four children to be consistent with the sample restrictions we have to make for the early childhood outcomes where sample size becomes too small for families with more than four children. ${ }^{3}$ These restrictions reduce the sample to 211,426 children from 97,316 families. In order to construct an accurate measure of birth order we further restrict the sample to include only families in which all children of the mother are still alive and live at home at the moment of the survey. In addition, we drop families with multiple births because of the ambiguity in assigning birth order in these families. Multiple births are defined as those children born within the same calendar year. This leaves us with a sample of 160,112 children living in 73,225 families.

We investigate the effect of birth order on secondary school enrollment and on child labor. A child is considered to be enrolled in secondary education if he or she is between 12 and 18 years old and the parent reports that the child was enrolled in school and attended school on a regular basis in the year of the survey. Since secondary education is compulsory until age 14 we investigate separately the effect of birth order on post-compulsory enrollment for children between 15 and 18

\footnotetext{
${ }^{3}$ Estimated birth order patterns are very similar when we extend the sample to include families with more than four children.
} 
years old. In our sample about 86 percent of the children between 12 and 14 is actually enrolled. The percentage of children between 15 and 18 years old that is enrolled in school is lower and equals 70 percent. Child labor is a dummy variable which equals 1 if the child's main economic activity in the past week was work outside the house. We investigate the effect of birth order on child labor for children between 12 and 18 years old as well for the sample of children that are no longer required to go to school. Table 1 gives some descriptive statistics.

Table 1: Descriptive statistics

\begin{tabular}{|c|c|c|c|c|c|c|}
\hline & \multicolumn{4}{|c|}{ SELBEN } & \multicolumn{2}{|c|}{ ENEVIN } \\
\hline & \multicolumn{2}{|c|}{$12-18$ years } & \multicolumn{2}{|c|}{$15-18$ years } & \multirow[b]{2}{*}{ Mean } & \multirow[b]{2}{*}{ SD } \\
\hline & Mean & $\mathrm{SD}$ & Mean & $\mathrm{SD}$ & & \\
\hline \multicolumn{7}{|l|}{ Child characteristics: } \\
\hline Gender ( 1 if female) & 0.472 & 0.499 & 0.458 & 0.498 & 0.488 & 0.499 \\
\hline Age (years) & 14.656 & 1.904 & 16.290 & 1.095 & & \\
\hline Enrollment & 0.779 & 0.414 & 0.704 & 0.456 & & \\
\hline Child labor & 0.109 & 0.312 & 0.170 & 0.376 & & \\
\hline Age (months) & & & & & 49.177 & 26.434 \\
\hline Age at test (months) & & & & & 40.179 & 18.586 \\
\hline Gross motor skills (sd) & & & & & 0.149 & 0.981 \\
\hline Fine motor skills (sd) & & & & & 0.138 & 0.995 \\
\hline Language skills (sd) & & & & & 0.162 & 0.989 \\
\hline Social skills (sd) & & & & & 0.152 & 0.976 \\
\hline Total preschool cognition (sd) & & & & & 0.165 & 0.979 \\
\hline Total time (minutes per day) & & & & & 303.920 & 148.951 \\
\hline Quality time (minutes per day) & & & & & 185.243 & 91.485 \\
\hline Cognitive care (minutes per day) & & & & & 52.017 & 61.323 \\
\hline Other care (minutes per day) & & & & & 133.226 & 68.787 \\
\hline Duration breastfeeding (months) & & & & & 12.327 & 6.571 \\
\hline \multicolumn{7}{|l|}{ Family characteristics: } \\
\hline Poverty index $(0-1)$ & 0.398 & 0.128 & 0.404 & 0.130 & 0.445 & 0.111 \\
\hline Family belongs to richest $50 \%$ & 0.203 & 0.402 & 0.216 & 0.411 & 0.303 & 0.459 \\
\hline Schooling of the household head & 7.611 & 3.967 & 7.651 & 4.010 & 7.728 & 3.670 \\
\hline Head has $\geq$ compulsory schooling & 0.270 & 0.444 & 0.274 & 0.446 & 0.297 & 0.457 \\
\hline Age mother (years) & 37.602 & 4.433 & 38.260 & 4.229 & 27.092 & 4.980 \\
\hline Age mother at first birth (years) & 21.126 & 3.937 & 21.118 & 3.882 & 19.845 & 4.368 \\
\hline Mother was teen at first birth & 0.373 & 0.484 & 0.368 & 0.482 & 0.542 & 0.498 \\
\hline Number of children in the family & 3.202 & 0.711 & 3.211 & 0.709 & 2.764 & 0.766 \\
\hline Number of observations & \multicolumn{2}{|c|}{160112} & \multicolumn{2}{|c|}{80343} & \multicolumn{2}{|c|}{3250} \\
\hline Number of families & \multicolumn{2}{|c|}{73225} & \multicolumn{2}{|c|}{57977} & \multicolumn{2}{|c|}{1434} \\
\hline
\end{tabular}




\subsection{ENEVIN}

The data that we use to estimate the effect of birth order on preschool cognition comes from a survey designed to evaluate the impact of early childhood development programs in Ecuador (ENEVIN). In 2008 survey data were collected for a sample of families with children below the age of six that were considered eligible for an early educational intervention because of their low socioeconomic status. Due to the selection criteria, the sample of families surveyed are poorer and younger, on average, than families in Ecuador as a whole. For the purpose of this study, we collected additional data and visited these families again in 2010. An important feature of the ENEVIN is that it includes a common and comprehensive battery of tests that measure the cognitive, motor and social development of children at early ages. Another feature of the ENEVIN is that the second round survey includes a time diary of the mother. In this she reports the time spent on various activities as well as the presence of up to four children during the activities. We will use this information to investigate how mother's time investment varies with birth order.

Cognitive development is assessed using a child's score on the Nelson-Ortiz test (Ortiz, 1999). The Nelson Ortiz is a validated test that measures four dimensions of child development: language skills, gross motor skills, fine motor skills and social behavior. A total score of child's cognitive development is computed by summing the scores obtained in each dimension. This test is suitable for children up to 72 months and is the official instrument used by Ecuadorian authorities to monitor the development of children in the early educational programs provided by the State. The Nelson Ortiz test is administered by asking the child to execute a number of tasks in each of the four dimension of development. Children of different ages start the test at different points and the test becomes gradually more difficult. For each dimension, the test score represents the total number of successfully executed tasks. In our analysis, we work with standardized test scores, which have mean zero and standard deviation one in the full sample.

We mainly use test score information we collected in the second survey round. If test score information is not available, we take the test score information from the first survey for those children who were below 72 months old in 2008. We include a dummy variable indicating whether 
we use test score information from the first instead of second survey and we include dummies for age of the child when taking the test (in months).

The data set contains test score information for 7120 children living in 4086 families. We restrict the sample to families in which the mother has a minimum of two and a maximum of four own birth children. We need a minimum of two children for our family fixed effects models. We restrict to a maximum of four children for two reasons; (1) time use data is available for a maximum of four children per family; (2) the data contains too few families with more than four children. These restrictions reduce the sample to 3892 children living in 1713 families. We further restrict the sample to families in which all children of the mother are still alive. We further drop families with multiple births and families in which the number of children that live at home at the moment of the second survey is smaller than the number of children the mother gave birth to (measured in the first survey). These restrictions are necessary to construct an accurate measure of birth order and leave us with a sample of 3250 children living in 1434 families. Table 1 shows summary statistics for the ENEVIN sample.

\section{Empirical model}

Estimating the effect of birth order on child outcomes is complicated due to the correlation of birth order with family size. Since family size, and all (unobserved) family characteristics that are correlated with family size, can have an independent effect on child outcomes, a naive regression of child outcomes on birth order will likely give inconsistent estimates. We deal with this endogeneity problem by including family fixed effects, more specifically we estimate the following specification by Least Squares:

$$
y_{i f}=\alpha+\beta_{2} \cdot \text { second }_{i f}+\beta_{3} \cdot \text { third }_{i f}+\beta_{4} \cdot \text { fourth }_{i f}+\lambda_{f}+X_{i f}^{\prime} \pi+\varepsilon_{i f}
$$

where $y_{i f}$ is the outcome of child $i$ in family $f, \lambda_{f}$ are family fixed effects and $X_{i f}$ include dummies for age and gender of the child. Since we use data on multiple children within a family, standard 
errors are clustered at the family level to correct for arbitrary within-family correlation.

The family fixed effects $\lambda_{f}$ absorb all (un)observed characteristics that are constant within a family, including family size, and the estimated coefficients on the dummies second if $_{\text {, }}$ third $_{i f}$ and fourth $_{\text {if }}$ can therefore be interpreted as the effect of having order 2, 3 or 4 compared to being a first born. A common problem with estimating birth order effects using within-family variation is that the correlation between birth order and age of the child is amplified. We deal with this by including dummies for child's age in all regressions.

The outcome variables of interest are school enrollment and child labor between age 12 and 18, and child cognition before age 6 . For both sets of outcome variables we work with an unbalanced panel where we observe the outcome for at least two but not necessarily all children in a family. We do not observe secondary school enrollment or labor participation for children below age 12 or above age 18 in the SELBEN, and we do not observe test scores for children older than 6 in the first survey round of the ENEVIN. Conditional on the family fixed effects, whether or not we observe the outcome for a child is fully determined by the age of the child at the moment of the survey. Since we control for age dummies in all specifications, the fact that we do not observe the dependent variable for all children in a family will not result in inconsistent estimates of the birth order effects. With heterogeneous effects, however, the estimated birth order coefficients can differ from the estimates we would obtain had we observed the outcomes for all children within each family. To check whether this is an issue we have estimated equation 1 on samples of families where we observe the human capital outcome for all children. These results, shown in Table A in the Appendix, are very similar to our main results which are presented in the next section.

\section{Results}

\subsection{Birth order effects on school enrollment and child labor}

Table 2 presents the estimated effects of birth order on secondary school enrollment and labor participation of children between 12 and 18 years old. For each outcome, the table reports estimates 
for two different model specifications. The first specification, labeled as OLS, includes dummies for age and gender of the child as well as a full set of dummies for the number of children in the family. In estimating birth order effects the main concern is the high correlation of birth order with family size (and other family characteristics related with family size). Including family size as control variable is a first step in addressing this identification problem, but a more convincing specification, labeled as FE, is based on equation (1) which includes family fixed effects.

The first column in Table 2 shows the OLS results and reveals a clear pattern; we find a significant positive association between birth order and secondary school enrollment. Relative to a base enrollment rate of 0.72 for the first born child, the size of the birth order effects is substantial. Column 1 also shows the estimated coefficients on the family size dummies. In contrast to the birth order results, these estimates are all negative and show that the probability that a child is enrolled in school is lower for children born in larger families. This negative association between school enrollment and family size is consistent with previous findings in the economic literature (Black et al., 2005; De Haan, 2010). We can however not give a causal interpretation to the estimated coefficients due to the fact that family size is likely correlated with (un)observed family characteristics.

Column 2 presents the results that include family fixed effects. These results show a similar birth order pattern as the results without family fixed effects. Relative to the first child, children of higher birth order are more likely to be enrolled in secondary school. These positive birth order patterns stand in sharp contrast to the negative birth order patterns found in western countries, but are consistent with the results found in other developing countries (Ejrnaes and Pörtner, 2004; Emerson and Souza, 2008; Tenikue and Verheyden, 2010).

As we already mentioned, a potential explanation for the positive effect of birth order on secondary school enrollment is that the oldest children drop out of school because they have to work in order to contribute to family income. Columns 3 and 4 of of Table 2 show the effect of birth order on labor participation for children between 12 and 18 years old. These results show indeed that first born children are significantly more likely to work compared to their later born siblings. 
The size of the estimated birth order effects become somewhat larger in absolute value when we include family fixed effects and show that a first born child is almost 10 percent more likely to work than his or her fourth born sibling.

Table 2 also shows results for a sample of children who are above the compulsory schooling age (15 to 18 years old). Columns 3 and 4 present the results for school enrollment and show the same positive pattern observed for the full sample of adolescents. Moreover, the estimated birth order effects are somewhat amplified as expected when schooling is no longer compulsory. Columns 7 and 8 present the results for labor participation and show a decrease in the probability of working as birth order increases. The size of the estimated birth order effects is similar to the effects obtained in the full sample of adolescents.

Table 2: The effect of birth order on secondary school enrollment and child labor

\begin{tabular}{|c|c|c|c|c|c|c|c|c|}
\hline & \multicolumn{2}{|c|}{$\begin{array}{l}\text { Secondary school } \\
\text { enrollment (12-18) }\end{array}$} & \multicolumn{2}{|c|}{$\begin{array}{l}\text { Post-compulsory } \\
\text { enrollment (15-18) }\end{array}$} & \multicolumn{2}{|c|}{$\begin{array}{l}\text { Child labor } \\
\text { (12-18) }\end{array}$} & \multicolumn{2}{|c|}{$\begin{array}{l}\text { Child labor } \\
(15-18)\end{array}$} \\
\hline & OLS & FE & OLS & $\mathrm{FE}$ & OLS & $\mathrm{FE}$ & OLS & $\mathrm{FE}$ \\
\hline Second & $\begin{array}{l}0.013 * * * \\
(0.002)\end{array}$ & $\begin{array}{l}0.008 * * \\
(0.003)\end{array}$ & $\begin{array}{c}0.021 * * * \\
(0.003)\end{array}$ & $\begin{array}{l}0.028 * * * \\
(0.008)\end{array}$ & $\begin{array}{c}-0.014 * * * \\
(0.002)\end{array}$ & $\begin{array}{c}-0.022 * * * \\
(0.003)\end{array}$ & $\begin{array}{c}-0.019 * * * \\
(0.003)\end{array}$ & $\begin{array}{c}-0.020 * * * \\
(0.008)\end{array}$ \\
\hline Third & $\begin{array}{l}0.051 * * * \\
(0.004)\end{array}$ & $\begin{array}{l}0.041 * * * \\
(0.006)\end{array}$ & $\begin{array}{c}0.064 * * * \\
(0.006)\end{array}$ & $\begin{array}{l}0.071 * * * \\
(0.017)\end{array}$ & $\begin{array}{c}-0.040 * * * \\
(0.003)\end{array}$ & $\begin{array}{c}-0.062 * * * \\
(0.005)\end{array}$ & $\begin{array}{c}-0.062 * * * \\
(0.005)\end{array}$ & $\begin{array}{c}-0.050 * * * \\
(0.015)\end{array}$ \\
\hline Fourth & $\begin{array}{c}0.105^{* * *} * \\
(0.007)\end{array}$ & $\begin{array}{l}0.081 * * * \\
(0.011)\end{array}$ & $\begin{array}{c}0.126 * * * \\
(0.017)\end{array}$ & $\begin{array}{c}0.140 * * * \\
(0.032)\end{array}$ & $\begin{array}{c}-0.068 * * * \\
(0.004)\end{array}$ & $\begin{array}{c}-0.094 * * * \\
(0.009)\end{array}$ & $\begin{array}{c}-0.098 * * * \\
(0.012)\end{array}$ & $\begin{array}{c}-0.079 * * * \\
(0.028)\end{array}$ \\
\hline \multicolumn{9}{|c|}{ Family size: } \\
\hline Three & $\begin{array}{c}-0.039 * * * \\
(0.003)\end{array}$ & & $\begin{array}{c}-0.044 * * * \\
(0.005)\end{array}$ & & $\begin{array}{c}0.027 * * * \\
(0.002)\end{array}$ & & $\begin{array}{l}0.041^{* * *} * \\
(0.004)\end{array}$ & \\
\hline Four & $\begin{array}{c}-0.127 * * * \\
(0.004)\end{array}$ & & $\begin{array}{c}-0.146 * * * \\
(0.005)\end{array}$ & & $\begin{array}{c}0.081 * * * \\
(0.002)\end{array}$ & & $\begin{array}{c}0.116 * * * \\
(0.004)\end{array}$ & \\
\hline $\mathrm{N}$ & 160112 & 160112 & 80343 & 80343 & 160112 & 160112 & 80343 & 80343 \\
\hline
\end{tabular}

\subsection{Birth order effects on preschool cognition}

Table 2 shows that first born children are significantly less likely to be enrolled in secondary education compared to their later born siblings. To investigate whether this positive birth order pattern is 
already observed early in life, we next investigate the effect of birth order on preschool cognition. Table 3 presents estimates of birth order effects on five dimensions of preschool cognition; gross motor skills, fine motor skills, language skills, social skills and the sum of these four skill measures, using a sample of children younger than 72 months from ENEVIN. As in the previous table, results are shown using a specification that includes family size dummies as well as a specification that relies on within-family variation for the identification of birth order effects.

The OLS results are shown in the first, third, fifth, seventh and ninth columns and are consistent with the findings presented for secondary school enrollment. Relative to the first child, later born children perform significantly better on the different cognitive tests. Birth order differentials are most pronounced on the tests for language and fine motor skills.

Fixed effect estimates are presented in the second, fourth, sixth, eighth and tenth columns. The estimated birth order effects are somewhat smaller in absolute value than the OLS estimates but, except for the result on social skills, the positive pattern between birth order and cognition is not sensitive to the inclusion of family fixed effects. The estimated effects are non-trivial; we find that a fourth born child has a performance that is about 10 percent of a standard deviation higher than that obtained by a first born sibling on the tests for language, fine motor, gross motor skills and the composite measure of cognitive skills.

In sum, we find that later born children have significantly higher human capital outcomes both in early childhood and in adolescence. Although the results for secondary school enrollment and preschool cognition are obtained using different data sets we believe that these findings can be interpreted as birth order effects being persistent, since the given data sets are comparable on important dimensions. As shown in Table 1 in both the SELBEN and ENEVIN poor, low educated families are overrepresented and family structure is very similar. 


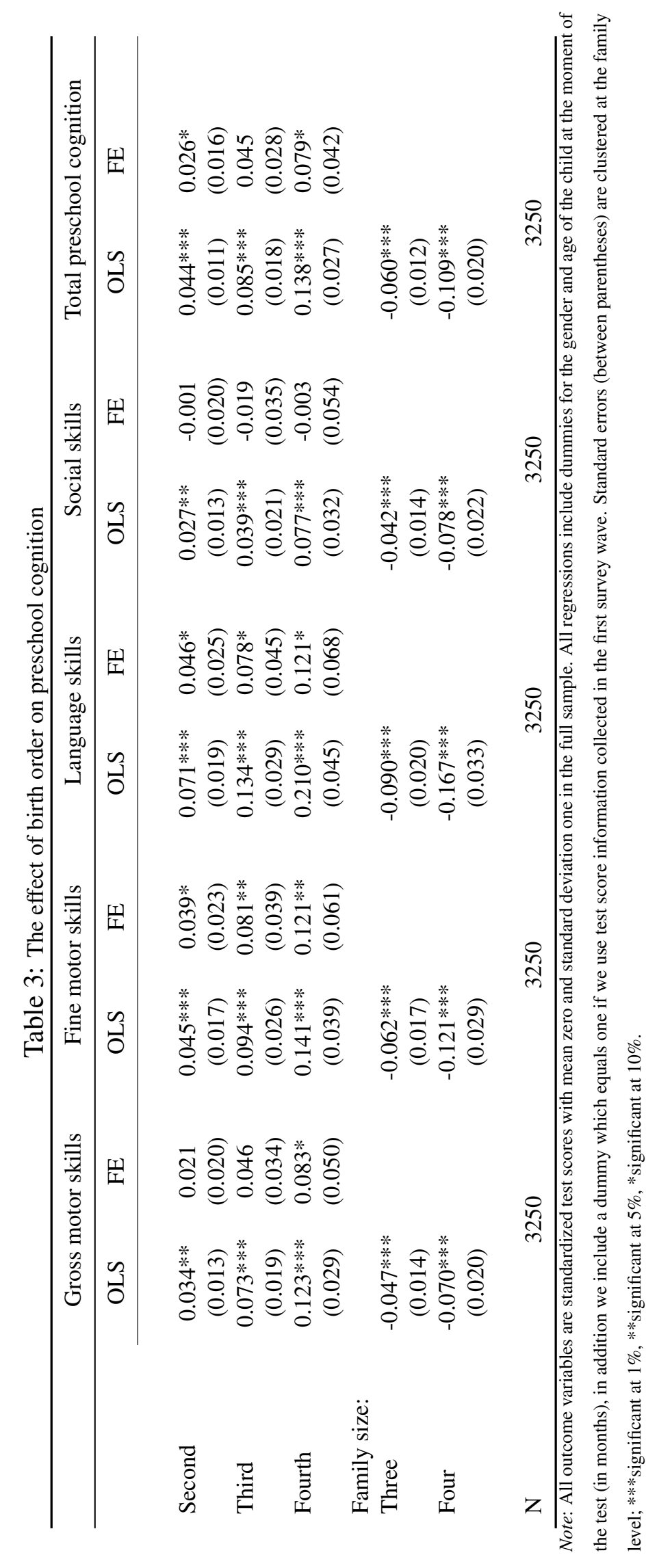




\section{What can explain the positive birth order patterns?}

In this section we investigate potential explanations for the persistent positive birth order patterns. In Sections 6.1 and 6.2 we investigate how mother's time investment and the duration of breastfeeding vary with birth order. In Section 6.3 we investigate whether important characteristics of developing countries (high poverty rates, low levels of parental education, high teenage pregnancy rates) can explain the positive birth order patterns as well as the sharp difference in birth order patterns between developed and developing countries.

\subsection{Mother's time investment}

One often mentioned mechanism behind birth order effects is differential time investment by parents. As described in Section 2, Price (2008) using the American Time Use Survey, finds that a first born child receives significantly more quality time with his or her parent than a second born child. He concludes that this is a plausible explanation for the negative birth order patterns in educational attainment observed in the U.S. (and other developed countries). Differential time investment by parents could also explain the birth order patterns found in this paper provided that the amount of time spent with parents increases instead of decreases with a child's birth order.

To investigate whether time spent with parents varies with a child's birth order, we use information from the second round of ENEVIN. In this second round survey each mother is asked to recall the activities performed on the previous working day. The day is divided in 20 one-hour intervals, from 4:00a.m. to 24:00p.m., and the mother is asked to mention up to three activities per hour. For each activity information is collected about the duration in minutes, the participation of any family members below the age of 18 and whether the activity was a multitask activity shared with other activities. For multitask activities we rescale the reported duration, such that the sum of the rescaled durations of all activities listed in each interval equals exactly 60 minutes. ${ }^{4}$ On the

\footnotetext{
${ }^{4}$ More specifically, we distinguish singletask activities from multitask activities which are done simultaneously with other activities. For singletask activities we use the reported duration. For multitask activities we rescale the reported duration with a factor equal to ((60- sum of duration spent on singletask activities)/sum of duration spent on multitask activities). We have also estimated the effect of birth order on mother's time investment using either reported
} 
basis of this information we compute the number of minutes per day that a child spent with his mother. ${ }^{5}$

Table 1 shows descriptive statistics for four measures of mother's time investment. Total time refers to the total amount of time that a child was present during any activity reported by the mother. While total time also includes time spent on activities in which the child was merely present, such as watching TV, cooking and cleaning the house, quality time includes only the activities in which the child was the main focus of the activity. Similar to Price (2008), we further subdivide quality time and make a distinction between cognitive care and other care. Cognitive care is the type of mother's time investment that is expected to have the biggest impact on human capital of children and includes activities such as playing, reading stories or books, talking, giving advice and helping with homework. Other care includes activities such as feeding, dressing, taking the child to the doctor and recreational, sports and religious activities. Table B in the Appendix lists the activities included in each of the four measures of mother's time use. Children spent on average a total of 304 minutes per day with their mother, of which 185 minutes are considered to be quality time. About 30 percent of quality time consists of cognitive care activities.

Table 4 shows fixed effects estimates of the effect of birth order on mother's time investment. Column 1 shows that there is a positive relation between total time spent with the mother and child's birth order, but the coefficients are rather imprecisely estimated and not significantly different from zero. If we focus only on activities which can be considered as quality time we see that the positive birth order pattern becomes stronger and second born children spent on average significantly more quality time with their mother compared to first born children. Columns 3 and 4 show the results when we make a distinction between cognitive care and other care. While time spent on other care activities has a negative (but insignificant) relation with birth order, mothers spent significantly more time on cognitive care activities with later born children. Compared to first born children, mothers devote about 20 minutes per day more on cognitive activities with fourth born

duration (where the total duration per interval could exceed 60 minutes) or time spent on the main activity reported in each interval. These results, which are very similar to the results shown in Table 4, are available on request.

${ }^{5}$ Following Price (2008), we treat time spent one-to-one with a single child in the same way as time spent with multiple children. 
children. This difference in time investment is about 30 percent of the standard deviation (reported in Table 1) and is therefore substantial. Overall, these results are consistent with differential time investment by the mother as possible driver behind the positive birth order patterns observed in preschool cognition and secondary school enrollment

Table 4: Fixed effects estimates of effect birth order on time spent with mother and time being breastfed

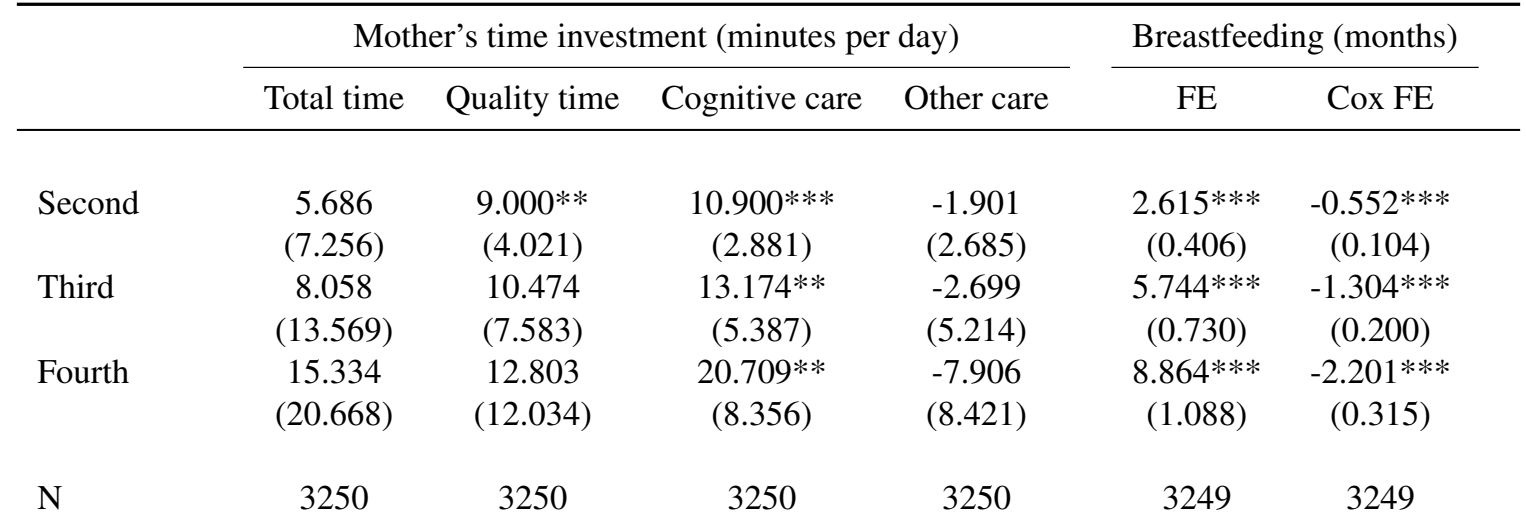

Note: All regressions include family fixed effects and dummies for the gender and age of the child (in months). Mother's time investment is collected from a questionnaire that asks mothers to recall the activities performed on the previous working day, whereby a day is divided in intervals of 60 minutes with a maximum of 3 activities per interval. Data is collected on the duration of each activity in minutes and on which children were participating in an activity. Duration of multitask activities are rescaled such that total time spend per hour equals 60 minutes. Data on breastfeeding is collected retrospectively by asking the mother how many months she breastfed each of her children. Standard errors (between parentheses) are clustered at the family level; ***significant at $1 \%, * *$ significant at $5 \%, *$ significant at $10 \%$.

\subsection{Breastfeeding}

There is a large literature that finds a positive effect of breastfeeding on child health in developing countries (Victora et al., 1987; Senauer and Kassouf, 2000; Betran et al., 2001). The literature on the effect of the duration of breastfeeding on cognitive outcomes is smaller but also indicates that being breastfed increases educational attainment (Rees and Sabia, 2009). If the duration of breastfeeding differs between children with a different birth order, this can also be a potential mechanism behind birth order differences in human capital outcomes.

Table 4 shows fixed effects estimates of the effect of birth order on breastfeeding duration using information from the ENEVIN survey. In the second survey round of ENEVIN, data on breastfeeding is collected by asking the mother how many months she breastfed each of her children. Table 4 
shows results for two different specifications. The specification labeled as FE estimates the effect of birth order on breastfeeding duration by OLS. Since some children are still being breastfed at the moment of the second survey round, we also estimate a Cox proportional hazard model to account for censored breastfeeding durations due to children still being nursed. ${ }^{6}$ Both specifications rely on within-family variation by the inclusion of family fixed effects. Table 4 shows that the duration that a child is being breastfed significantly increases with birth order. The Least Squares results indicate that a fourth born child is breastfed for about 8 months longer than his or her first born sibling. Also the negative birth order coefficients from the Cox proportional hazard model show that mothers wean there first born child much sooner than their later born children.

These results show that mother's breastfeed later born children significantly longer than first born children. These positive birth order patterns are consistent with those found for human capital outcomes and similar to the results found by Jayachandran and Kuziemko (2011) for India.

\subsection{Poverty, parental schooling and teenage motherhood}

As mentioned earlier, there are a number of potential reasons why earlier born children in developing countries do worse. Parents can be too poor; if poor parents send their earlier born children out to work and obtain more resources to allocate to later born children, then later born children are more likely to end up having more schooling. Alternatively, first time parents can be too young and inexperienced. If first time parents learn and turn into better parents, they may offer their later born children a more nurturing environment. By this logic we expect that the positive birth order patterns are magnified in poor, low educated families and in families in which the mother was a teen at first birth. Table 5 reports estimates from fully interacted fixed effects models where all birth order, age and gender dummies are interacted with variables that indicate whether a family is rich (or less poor), whether the family head has a high level of education, and whether the mother was a teen when she had her first child. For reasons of brevity, we only report estimates for general

\footnotetext{
${ }^{6}$ We report coefficients from a Cox proportional hazard model where a negative birth order coefficient implies that mothers are less likely to stop breastfeeding for later born children.
} 
preschool cognition, secondary school enrollment and child labor between age 12 and $18 .^{7}$

In the top panel we let birth order effects vary with poverty levels. We define a poverty index based on the SELBEN index, which is used by the Ecuadorian government to target programs aimed at helping poor families. The SELBEN index is based on a measure of socioeconomic status which aggregates information about demographic composition, educational attainment, employment, possession of assets and durable goods, dwelling characteristics and access to services. Families are ranked by their relative position which results in the SELBEN index. Since this index is partly based on endogenous variables such as school enrollment of children and family size we construct a poverty index that follows the same methodological approach, but leaves out these endogenous variables. ${ }^{8}$ The resulting poverty index is a variable with values between 0 and 1 , where a value above 0.5 implies that the family belongs to the richest 50 percent of families in Ecuador.

The first three columns report results where birth order variables are interacted with a dummy variable which equals one if the poverty index is above 0.5 . The estimates for school enrollment in the first column show that the positive birth order patterns are indeed strongest in poorer families. The interacted birth order effects, which represent the birth order difference between poorer and richer families, are all negative and especially for later born children significantly different from zero. The estimates for child labor in the second column are comparable; the birth order effects are particularly strong in poorer families, and significantly stronger than the effects we find in richer families. In contrast, all the birth order effects for preschool cognition in the third column are statistically insignificant and do not suggest that there are any systematic birth order differences between children raised in poorer and richer families.

Since the SELBEN and ENEVIN are surveys targeted at poor families we do not have informa-

\footnotetext{
${ }^{7} \mathrm{We}$ also have compared these results with those obtained for the other outcome variables (including the four separate preschool cognition test scores, child schooling and labor between age 15 and 18). We did not find any systematic differences. These results are available upon request.

${ }^{8} \mathrm{We}$ recalculated the weights for the remaining variables in the poverty index using the same methodology (non linear principal components) and the same representative sample of all Ecuadorian families applied to construct the SELBEN index. These weights are used to calculate the relative poverty index for each of the families in the SELBEN and the ENEVIN data sets. Table C in the Appendix shows which family characteristics are included in the SELBEN index and which are excluded for the poverty index used in our analyses.
} 
tion about the richest families in Ecuador. ${ }^{9}$ To get some idea what the birth order effects would be in those richest families, the last three columns of the top panel show estimates where the continuous poverty index is used as interacting variable. Also with continuous interactions we find birth order effects for child schooling and child labor that are strongest for the very poor families. The birth order estimates for preschool cognition lack precision and are not informative. If we use the estimated interaction terms to predict birth order patterns in families that belong to the richest 10 percent in Ecuador, we find that birth order effects would even reverse for the very rich families. This finding that earlier born children in poor families, who are sent out to work, would rather go to school had they been raised in rich families is quite remarkable, and suggests that poverty might explain the striking difference in birth order patterns between developed and developing countries. That we do not find much for children in their preschool years does not contradict this story, because these children are too young to work.

Another proxy for poverty or financial constraints is parents' education. In the middle panel we report how the effect of birth order varies with the schooling of the head of the family (in most cases the father). In the first three columns we show birth order effects interacted with a dummy variable indicating whether the family head has more than compulsory lower secondary education. The results are very similar to the results in the top panel and show that birth order effects are significantly stronger for children with lower educated family heads. The birth order effects for early child cognition, on the other hand, do not differ much across schooling groups.

In the last three columns we also show birth order effects interacted with a continuous variable measuring the schooling of the head of the family in years. Again, the results are largely similar, showing that the birth order effects on school enrollment and child labor are larger for children born to less educated parents. As with all the interacted estimates for early childhood cognition, the estimates in the last column are much less precisely estimated and not informative.

\footnotetext{
${ }^{9}$ The 99th percentile of the poverty index is 0.74 in the SELBEN and 0.72 in the ENEVIN.
} 
Table 5: Fixed effects estimates of birth order, interacted with different indicators of socioeconomic status

\begin{tabular}{|c|c|c|c|c|c|c|}
\hline & $\begin{array}{c}\text { Enrollment } \\
12-18\end{array}$ & $\begin{array}{c}\text { Child labor } \\
12-18\end{array}$ & $\begin{array}{l}\text { Preschool } \\
\text { cognition }\end{array}$ & $\begin{array}{c}\text { Enrollment } \\
12-18\end{array}$ & $\begin{array}{c}\text { Child labor } \\
12-18\end{array}$ & $\begin{array}{l}\text { Preschool } \\
\text { cognition }\end{array}$ \\
\hline Interaction: & \multicolumn{3}{|c|}{ Poverty index is above 0.5} & \multicolumn{3}{|c|}{ Linear poverty index } \\
\hline Second & $\begin{array}{c}0.000 \\
(0.004)\end{array}$ & $\begin{array}{c}-0.017 * * * \\
(0.003)\end{array}$ & $\begin{array}{c}0.013 \\
(0.018)\end{array}$ & $\begin{array}{l}-0.000 \\
(0.010)\end{array}$ & $\begin{array}{c}-0.034 * * * \\
(0.009)\end{array}$ & $\begin{array}{c}-0.018 \\
(0.060)\end{array}$ \\
\hline Third & $\begin{array}{c}0.030 * * * \\
(0.008)\end{array}$ & $\begin{array}{c}-0.054 * * * \\
(0.006)\end{array}$ & $\begin{array}{c}0.022 \\
(0.033)\end{array}$ & $\begin{array}{c}0.053 * * * \\
(0.021)\end{array}$ & $\begin{array}{c}-0.089 * * * \\
(0.018)\end{array}$ & $\begin{array}{l}-0.009 \\
(0.105)\end{array}$ \\
\hline Fourth & $\begin{array}{c}0.067 * * * \\
(0.014)\end{array}$ & $\begin{array}{c}-0.081 * * * \\
(0.011)\end{array}$ & $\begin{array}{c}0.045 \\
(0.050)\end{array}$ & $\begin{array}{c}0.138 * * * \\
(0.036)\end{array}$ & $\begin{array}{c}-0.136 * * * \\
(0.030)\end{array}$ & $\begin{array}{c}0.008 \\
(0.164)\end{array}$ \\
\hline 2 nd $\times$ interaction & $\begin{array}{l}-0.001 \\
(0.006)\end{array}$ & $\begin{array}{c}0.011 * * \\
(0.005)\end{array}$ & $\begin{array}{c}0.008 \\
(0.033)\end{array}$ & $\begin{array}{l}-0.012 \\
(0.022)\end{array}$ & $\begin{array}{c}0.059 * * * \\
(0.019)\end{array}$ & $\begin{array}{c}0.062 \\
(0.130)\end{array}$ \\
\hline $3 r d \times$ interaction & $\begin{array}{l}-0.018 \\
(0.012)\end{array}$ & $\begin{array}{c}0.022 * * \\
(0.010)\end{array}$ & $\begin{array}{c}0.002 \\
(0.058)\end{array}$ & $\begin{array}{c}-0.090^{* *} \\
(0.044)\end{array}$ & $\begin{array}{c}0.119 * * * \\
(0.037)\end{array}$ & $\begin{array}{c}0.047 \\
(0.228)\end{array}$ \\
\hline 4 th $\times$ interaction & $\begin{array}{c}-0.039 * \\
(0.021)\end{array}$ & $\begin{array}{l}0.029 * \\
(0.017)\end{array}$ & $\begin{array}{l}-0.010 \\
(0.090)\end{array}$ & $\begin{array}{c}-0.225 * * * \\
(0.076)\end{array}$ & $\begin{array}{c}0.178 * * * \\
(0.063)\end{array}$ & $\begin{array}{c}0.029 \\
(0.358)\end{array}$ \\
\hline Interaction: & \multicolumn{3}{|c|}{ Head has more than compulsory schooling } & \multicolumn{3}{|c|}{ Linear schooling of the head } \\
\hline Second & $\begin{array}{c}0.003 \\
(0.004)\end{array}$ & $\begin{array}{c}-0.020 * * * \\
(0.003)\end{array}$ & $\begin{array}{c}0.023 \\
(0.018)\end{array}$ & $\begin{array}{c}0.006 \\
(0.007)\end{array}$ & $\begin{array}{c}-0.025^{* * *} * \\
(0.006)\end{array}$ & $\begin{array}{c}0.040 \\
(0.039)\end{array}$ \\
\hline Third & $\begin{array}{c}0.034 * * * \\
(0.008)\end{array}$ & $\begin{array}{c}-0.057 * * * \\
(0.007)\end{array}$ & $\begin{array}{c}0.036 \\
(0.032)\end{array}$ & $\begin{array}{c}0.054 * * * \\
(0.014)\end{array}$ & $\begin{array}{c}-0.076^{* * *} * \\
(0.012)\end{array}$ & $\begin{array}{c}0.038 \\
(0.067)\end{array}$ \\
\hline Fourth & $\begin{array}{c}0.069 * * * \\
(0.014)\end{array}$ & $\begin{array}{c}-0.080 * * * \\
(0.012)\end{array}$ & $\begin{array}{c}0.058 \\
(0.049)\end{array}$ & $\begin{array}{c}0.107 * * * \\
(0.025)\end{array}$ & $\begin{array}{c}-0.100 * * * \\
(0.021)\end{array}$ & $\begin{array}{c}0.064 \\
(0.099)\end{array}$ \\
\hline 2 nd $\times$ interaction & $\begin{array}{c}0.005 \\
(0.006)\end{array}$ & $\begin{array}{c}0.008 \\
(0.005)\end{array}$ & $\begin{array}{c}0.001 \\
(0.036)\end{array}$ & $\begin{array}{c}-0.000 \\
(0.001)\end{array}$ & $\begin{array}{l}0.001^{*} \\
(0.001)\end{array}$ & $\begin{array}{l}-0.003 \\
(0.005)\end{array}$ \\
\hline $3 r d \times$ interaction & $\begin{array}{l}-0.018 \\
(0.012)\end{array}$ & $\begin{array}{c}0.029 * * * \\
(0.009)\end{array}$ & $\begin{array}{c}0.011 \\
(0.063)\end{array}$ & $\begin{array}{c}-0.004 * * * \\
(0.001)\end{array}$ & $\begin{array}{c}0.004 * * * \\
(0.001)\end{array}$ & $\begin{array}{l}-0.002 \\
(0.008)\end{array}$ \\
\hline 4 th $\times$ interaction & $\begin{array}{c}-0.049 * * \\
(0.022)\end{array}$ & $\begin{array}{c}0.039 * * \\
(0.017)\end{array}$ & $\begin{array}{c}0.036 \\
(0.095)\end{array}$ & $\begin{array}{c}-0.007 * * * \\
(0.003)\end{array}$ & $\begin{array}{c}0.005^{* *} \\
(0.002)\end{array}$ & $\begin{array}{l}-0.004 \\
(0.012)\end{array}$ \\
\hline Interaction: & \multicolumn{3}{|c|}{ Mother was not a teen at first birth } & \multicolumn{3}{|c|}{ Linear age of the mother at first birth } \\
\hline Second & $\begin{array}{l}0.010 * \\
(0.006)\end{array}$ & $\begin{array}{c}-0.026 * * * \\
(0.005)\end{array}$ & $\begin{array}{c}0.018 \\
(0.022)\end{array}$ & $\begin{array}{c}0.023 \\
(0.018)\end{array}$ & $\begin{array}{c}-0.057 * * * \\
(0.015)\end{array}$ & $\begin{array}{c}0.098 \\
(0.089)\end{array}$ \\
\hline Third & $\begin{array}{c}0.047 * * * \\
(0.011)\end{array}$ & $\begin{array}{c}-0.066^{* * *} \\
(0.010)\end{array}$ & $\begin{array}{c}0.031 \\
(0.037)\end{array}$ & $\begin{array}{c}0.073 * * \\
(0.036)\end{array}$ & $\begin{array}{c}-0.106 * * * \\
(0.029)\end{array}$ & $\begin{array}{c}0.219 \\
(0.167)\end{array}$ \\
\hline Fourth & $\begin{array}{c}0.099 * * * \\
(0.020)\end{array}$ & $\begin{array}{c}-0.107 * * * \\
(0.016)\end{array}$ & $\begin{array}{c}0.061 \\
(0.057)\end{array}$ & $\begin{array}{c}0.145^{* *} \\
(0.065)\end{array}$ & $\begin{array}{c}-0.173 * * * \\
(0.055)\end{array}$ & $\begin{array}{c}0.338 \\
(0.257)\end{array}$ \\
\hline 2nd $\times$ interaction & $\begin{array}{l}-0.004 \\
(0.007)\end{array}$ & $\begin{array}{c}0.007 \\
(0.006)\end{array}$ & $\begin{array}{c}0.02 \\
(0.032)\end{array}$ & $\begin{array}{l}-0.001 \\
(0.001)\end{array}$ & $\begin{array}{c}0.002 * * \\
(0.001)\end{array}$ & $\begin{array}{l}-0.004 \\
(0.004)\end{array}$ \\
\hline $3 r d \times$ interaction & $\begin{array}{l}-0.010 \\
(0.014)\end{array}$ & $\begin{array}{c}0.007 \\
(0.012)\end{array}$ & $\begin{array}{c}0.032 \\
(0.058)\end{array}$ & $\begin{array}{l}-0.001 \\
(0.002)\end{array}$ & $\begin{array}{c}0.002 \\
(0.001)\end{array}$ & $\begin{array}{c}-0.009 \\
(0.008)\end{array}$ \\
\hline 4 th $\times$ interaction & $\begin{array}{l}-0.029 \\
(0.024)\end{array}$ & $\begin{array}{c}0.022 \\
(0.020)\end{array}$ & $\begin{array}{c}0.045 \\
(0.088)\end{array}$ & $\begin{array}{l}-0.003 \\
(0.003)\end{array}$ & $\begin{array}{c}0.004 \\
(0.003)\end{array}$ & $\begin{array}{l}-0.013 \\
(0.013)\end{array}$ \\
\hline
\end{tabular}

Note: Estimates come from fully interacted fixed effects models where all birth order dummies and included control variables are interacted with variables that indicate the poverty level, the level of education of the family head, or age of the mother at first birth. Regressions for enrollment and child labor include dummies for age in years and gender of the child. Preschool cognition corresponds to the sum of the scores in the four dimensions of the Nelson-Ortiz test and is standardized to have mean zero and standard deviation one in the full sample. Regressions for preschool cognition include dummies for gender and age of the child in months and a dummy which equals one if test score information is collected in the first survey wave. Standard errors (between parentheses) are clustered at the family level; ***significant at $1 \%$, **significant at $5 \%$, *significant at $10 \%$. The number of observations for the enrollment and child labor regressions is equal to 160.112 while for the precognition regressions is equal to 3.250 . 
Using the estimated interaction terms we can predict birth order patterns for children brought up by family heads with an university degree. ${ }^{10}$ In line with the results using the poverty index, we find that the birth order effects for secondary school enrollment turn slightly negative. If families with lower educated family heads are more financially constrained than those with more educated family heads, these findings behave as if financial constraints were driving our results.

In the bottom panel in Table 5 we report estimates of the effect of birth order on secondary school enrollment, child labor and preschool cognition using birth order fixed effects models interacted with either a dummy variable that equals one if the mother was 19 or younger when she gave birth to her first child or a continuous variable that measures the mother's age at first birth. As one can see, the interacted birth order effects are all small and not significantly different from zero. Because birth order effects are quite similar for younger and older mothers, the birth order patterns observed in our data have little, if anything, to do with teenage motherhood.

\section{Concluding remarks}

In this paper we examine the effect of birth order on human capital development in Ecuador. With a large national database on poor families in Ecuador, we find that later born children are significantly more likely to go to school and significantly less likely to work. These findings are neither driven by family characteristics that siblings share nor by sibling differences in age. The positive birth order effects we find are similar to those found in other developing countries but the opposite of what is found in developed countries. We find that the birth order effects are particularly strong for children growing up in poor, low educated families, and even tend to reverse in richer families. Poverty (and the absence thereof) therefore seems a likely driver behind the birth order divide observed between developing and developed countries.

In this paper we also investigate in detail the effect of birth order and human capital development in early childhood. Specifically, we examine the extent to which birth order influences child

\footnotetext{
${ }^{10} \mathrm{~A}$ university degree is equivalent to 17 years of education.
} 
cognition before age 6 , and the extent to which birth order affects the time mothers invest in her children. Lacking nationally representative family data with direct information on child cognition and maternal time use, we have collected the data ourselves and held a survey in 2010 under a selective sample of poor families with children eligible for early child development programs. To the best of our knowledge, the relationship between birth order, child cognition and maternal time investments have not been studied previously in the context of a developing country.

For child cognition, we find that our birth order estimates mirror those found for children of secondary school age; that is, earlier born children lag behind in their cognitive development. Since the two data sets consist of comparable families, our main findings indicate that the birth order patterns observed in adolescence are already present in early childhood before children start school. For time investments, we find that mothers spend less time with earlier born children, and that mothers spend considerably less time with earlier born children on cognitive activities (including playing together, reading books and talking with children). We also find that earlier born children are breastfed less.

How are we to interpret these findings? Finding an answer is difficult because the observed differences in schooling can both be cause and consequence of the observed differences in parental treatment. If, for example, earlier born children face adverse conditions in utero (because of limited prenatal care), earlier born children might already lag behind at birth and demand less cognitive care. If, on the other hand, earlier and later born children are born with comparable skills but mothers invest less time in earlier born children, earlier born children might lag behind because of less cognitive care. One possible answer may lie in the opposite time investment patterns found in the context of a developed country. With later born children doing worse, Price (2008) documents that mothers in the U.S. spend significantly more time with their earlier born children, and not less.

Overall, the main message of our study is that birth order effects in Ecuador are persistently positive: (i) later born children are breastfed more; (ii) later born children spend more time with their mothers on cognitive activities; (iii) later born children are ahead in their cognitive development in early childhood; and (iv) later born children are more likely go to school during their 
adolescent years.

What are the possible implications of these birth order results? First, there are implications for those explanatory theories aimed at better understanding the negative birth order pattern observed in developed countries. Our findings suggest that many of these theories may not be that important in the context of a developing country. Second, there are implications for policymakers. Many nutritional and cash transfer programs, for instance, provide nutritional and financial assistance to poor families and are aimed at improving the children's health and human capital. But if improving the conditions for children in need is the main policy objective, then our birth order findings suggest that policies should be designed to improve the conditions of particularly earlier born children. Our findings further suggest that any serious evaluation of the effectiveness of such policy programs should recognize that there are birth order differentials within families and take into account that the children's response to these programs might depend on birth order as well.

\section{References}

Almond, D. and Currie, J. (2011). Human capital development before age five. In Ashenfelter, O. and Card, D., editors, Handbook of Labor Economics, volume 4, chapter 15, pages 1315-1486. Elsevier Science Publishers B.V.

Barcellos, S., Carvalho, L., and Lleras-Muney, A. (2012). Child gender and parental investments in India: Are boys and girls treated differently? Technical report, NBER Working Paper No. 17781.

Basu, K. and Van, P. (1998). The economics of child labor. American Economics Review, 88(3):412-427.

Becker, G. (1965). A theory of the allocation of time. Economic Journal, 75:493-517.

Betran, A., de Onis, M., Lauer, J., and Villar, J. (2001). Ecological study of effect of breast feeding on infant mortality in Latin America. British Medical Journal, 323:1-5. 
Björklund, A. and Salvanes, K. (2011). Education and family background: Mechanisms and policies. Handbook of the Economics of Education, 3:201-247.

Black, S., Devereux, P., and Salvanes, K. (2005). The more the merrier?. The effect of family size and birth order on children's education. Quarterly Journal of Economics, 120(2):669-700.

Blake, J. (1989). Family Size and Achievement. Berkeley and Los Angeles, CA; University of California Press.

Booth, A. and Kee, H. (2009). Birth order matters: The effect of family size and birth order on educational attainment. Journal of Population Economics, 22(2):367-397.

Conley, D. and Glauber, R. (2006). Parental educational investment and children's academic risk: Estimates of the impact of sibship size and birth order from exogenous variation in fertility. Journal of Human Resources, 41(4):722-737.

Cunha, F., Heckman, J. J., Lochner, L., and Masterov, D. V. (2006). Interpreting the evidence on life cycle skill formation. In Hanushek, E. and Welch, F., editors, Handbook of the Economics of Education. Elsevier Science Publishers B.V., Amsterdam.

De Haan, M. (2010). Birth order, family size and educational attainment. Economics of Education Review, 29:576-588.

Edmonds, E. (2006). Understanding sibing differences in child labor. Journal of Population Economics, 19:795-821.

Ejrnaes, M. and Pörtner, C. (2004). Birth order and the intrahousehold allocation of time and education. Review of Economics and Statistics, 86(4):1008-1019.

Emerson, P. and Souza, A. P. (2008). Birth order, child labor and school attendance in brazil. World Development, 36(9):1647-1664.

Francesconi, M. (2008). Adult outcomes for children of teenage mothers. The Scandinavian Journal of Economics, 110(1):93-117. 
Galton, F. (1874). English Men of Science: Their nature and nurture. Macmillan \& Co.

Gary-Bobo, R., Picard, N., and Prieto, N. (2006). Birth order and sibship sex composition as instruments in the study of education and earnings. Technical report, CEPR Discussion Papers 5514.

Gualtiery, T. and Hicks, R. (1985). An immunoreactive theory of selective male affliction. Behavioral \& Brain Science, 8:427-441.

Guryan, J., Hurst, E., and Kearney, M. (2008). Parental education and parental time with children. Journal of Economic Perspectives, 22(3):23-46.

Jayachandran, S. and Kuziemko, I. (2011). Why do mothers breastfeed girls less than boys?. Evidence and implications for child health in India. Quarterly Journal of Economics, 126:14851538.

Kantarevic, J. and Mechoulan, S. (2006). Birth order, educational attainment, and earnings: An investigation using the PSID. Journal of Human Resources, 41(4):755-777.

Kidd, S., Eskenazi, B., and Wyrobek, A. (2001). Effects of male age on semen quality and fertility: a review of the literature. Fertility and sterility, 75(2):237-248.

Kristensen, P. and Bjerkedal, T. (2007). Explaining the relation between birth order and intelligence. Science, 316:1717.

Ortiz, N. (1999). Escala abreviada de desarrollo. Technical report, Ministerio de Salud de Colombia y UNICEF.

Price, J. (2008). Parent-Child quality time. Journal of Human Resources, 43(1):240-265.

Rees, D. and Sabia, J. (2009). The effect of breast feeding on educational attainment: Evidence from sibling data. Journal of Human Capital, 3(1):43-72. 
Senauer, B. and Kassouf, A. (2000). The effects of breastfeeding on health and the demand for medical assistance among children in Brazil. Economic Development and Cultural Change, 48(4):719-736.

Tenikue, M. and Verheyden, B. (2010). Birth order and schooling: Theory and evidence from twelve sub-saharan countries. Journal of African Economies, 19(4):459-495.

Victora, C. G., Smith, P. G., Vaughan, J. P., Nobre, L. C., Lombardi, C., Teixeira, A. M., Fuchs, S. M., Moreira, L. B., Gigante, L. P., and Barros, F. C. (1987). Evidence for the protection by breastfeeding against infant deaths from infectious diseases in Brazil. Lancet, 2:319-322.

Zajonc, R. (1976). Family configuration and intelligence. Science, 192:227-236. 


\section{Appendix}

Table A: Fixed effects estimates of birth order; samples with all children of mother in specified age range

\begin{tabular}{lllll}
\hline & $\begin{array}{l}\text { Secondary school } \\
\text { enrollment }(12-18)\end{array}$ & $\begin{array}{l}\text { Post-compulsory } \\
\text { enrollment }\end{array}$ & $\begin{array}{l}\text { Child labor } \\
(12-18)\end{array}$ & $\begin{array}{l}\text { Child labor } \\
(15-18)\end{array}$ \\
\hline Second & -0.004 & 0.029 & $-0.011^{* *}$ & -0.010 \\
& $(0.006)$ & $(0.021)$ & $(0.005)$ & $(0.018)$ \\
Third & $0.025^{* *}$ & $0.081^{* *}$ & $-0.061^{* * *}$ & $-0.066^{*}$ \\
& $(0.011)$ & $(0.041)$ & $(0.009)$ & $(0.035)$ \\
Fourth & $0.095^{* * *}$ & & $-0.131^{* * *}$ & \\
& $(0.020)$ & & $(0.017)$ & \\
$\mathrm{N}$ & 42617 & 6582 & 42617 & 6582 \\
& & & & \\
\hline Preschool cognition: & Gross motor skills & Fine motor skills & Language skills & Social skills \\
\hline Second & 0.024 & 0.036 & $0.059^{*}$ & 0.032 \\
& $(0.027)$ & $(0.027)$ & $(0.034)$ & $(0.026)$ \\
Third & 0.064 & $0.103^{* *}$ & $0.143^{* *}$ & 0.038 \\
& $(0.046)$ & $(0.048)$ & $(0.061)$ & $(0.046)$ \\
Fourth & $0.135^{* *}$ & $0.233^{* * *}$ & $0.242^{* *}$ & 0.061 \\
& $(0.067)$ & $(0.078)$ & $(0.094)$ & $(0.062)$ \\
$\mathrm{N}$ & 2095 & 2095 & 2095 & 2095 \\
\hline
\end{tabular}

Note: Sample includes only families whereby we observe the schooling outcome for all children. All regressions include family fixed effects. Regressions in top panel include dummies for age (in years) and gender of the child. Secondary school enrollment is a dummy which equals one if the child was enrolled in school and attended school on a regular basis in the year of the survey. Child labor is a dummy variable which equals one if the child's main economic activity in the past week was work outside the house. Outcome variables in bottom panel are standardized test scores with mean zero and standard deviation one in the full sample. Regressions in bottom panel include dummies for the gender and age of the child (in months), in addition we include a dummy which equals one if we use test score information collected in the first survey wave. Standard errors (between parentheses) are clustered at the family level; ***significant at 1\%, **significant at 5\%, *significant at $10 \%$. 
Table B: Mother's time use

\begin{tabular}{|c|c|c|c|c|}
\hline & Total time & Quality time & Cognitive care & Other care \\
\hline 1. & Sleeping & & & \\
\hline 2. & Dressing, bathing, grooming & & & \\
\hline 3. & Watch TV or listen to music & & & \\
\hline 4. & Working & & & \\
\hline 5. & Prepare meals or snacks & & & \\
\hline 6. & Breakfast, lunch, snacks & $\mathrm{x}$ & & $\mathrm{x}$ \\
\hline 7. & Cleaning the house & & & \\
\hline 8. & Cleaning the dishes & & & \\
\hline 9. & Washing and ironing clothes & & & \\
\hline 10. & Purchase of food & & & \\
\hline 11. & Gathering food (agriculture) & & & \\
\hline 12. & Religious activities & $\mathrm{x}$ & & $\mathrm{x}$ \\
\hline 13. & Pay bills, and personal business & & & \\
\hline 14. & Sports activities & $\mathrm{x}$ & & $\mathrm{x}$ \\
\hline 15. & Personal entertainment activities & & & \\
\hline 16. & Family entertainment activities & $\mathrm{x}$ & & $\mathrm{X}$ \\
\hline 17. & Feeding, dressing and cleaning children & $\mathrm{X}$ & & $\mathrm{x}$ \\
\hline 18. & Playing with children, painting, drawing & $\mathrm{X}$ & $\mathrm{X}$ & \\
\hline 19. & Reading stories, books to children & $\mathrm{X}$ & $\mathrm{X}$ & \\
\hline 20. & Helping children with homework & $\mathrm{X}$ & $\mathrm{X}$ & \\
\hline 21. & Talking with the children & $\mathrm{x}$ & $\mathrm{x}$ & \\
\hline 22. & Going to the doctor, taking care of an ill child & $\mathrm{x}$ & & $\mathrm{x}$ \\
\hline 23. & Picking up/ dropping off & & & \\
\hline 24. & Rest, lying down & & & \\
\hline 25. & Go to health centers or hospitals & & & \\
\hline 26. & Taking care of elderly people & & & \\
\hline 27. & Making phone calls & & & \\
\hline 28. & Attend classes or training courses & & & \\
\hline 29 & Other & & & \\
\hline
\end{tabular}


Table C: Variables included in the SELBEN index and in the poverty index used in the analysis

\begin{tabular}{|c|c|c|c|}
\hline & Variables & SELBEN index & Poverty index \\
\hline 1. & Area (urban/rural) & $\mathrm{x}$ & $\mathrm{x}$ \\
\hline 2. & Quality of the floor & $\mathrm{x}$ & $\mathrm{x}$ \\
\hline 3. & Access to electricity & $\mathrm{x}$ & $\mathrm{x}$ \\
\hline 4. & Shower availability & $\mathrm{x}$ & $\mathrm{x}$ \\
\hline 5. & Access to sanitation & $\mathrm{x}$ & $\mathrm{x}$ \\
\hline 6. & Type of energy used for cooking & $\mathrm{x}$ & $\mathrm{x}$ \\
\hline 7. & Overcrowding & $\mathrm{x}$ & \\
\hline 8. & Number of children younger than 6 years old & $\mathrm{x}$ & \\
\hline 9. & Number of income earners & $\mathrm{x}$ & \\
\hline 10. & Ethnic background of the family head & $\mathrm{x}$ & $\mathrm{x}$ \\
\hline 11. & Educational level of the family head & $\mathrm{x}$ & $\mathrm{x}$ \\
\hline 12. & Access to health insurance of the family head & $\mathrm{x}$ & $\mathrm{x}$ \\
\hline 13. & Educational level of the spouse & $\mathrm{x}$ & $\mathrm{x}$ \\
\hline 14. & Access to credit & $\mathrm{x}$ & $\mathrm{x}$ \\
\hline 15. & Number of children 6 to 15 not enrolled in school & $\mathrm{x}$ & \\
\hline 16. & Type of school of children 6 to 15 enrolled & $\mathrm{x}$ & \\
\hline 17. & Number of handicapped family members & $\mathrm{x}$ & \\
\hline 18. & Land ownership & $\mathrm{x}$ & $\mathrm{x}$ \\
\hline 19. & Availability of a TV & $\mathrm{x}$ & $\mathrm{x}$ \\
\hline 20. & Availability of a DVD & $\mathrm{x}$ & $\mathrm{x}$ \\
\hline 21. & Availability of a car & $\mathrm{x}$ & $\mathrm{x}$ \\
\hline 22. & Availability of a refrigerator & $\mathrm{x}$ & $\mathrm{x}$ \\
\hline 23. & Availability of a stove & $\mathrm{x}$ & $\mathrm{x}$ \\
\hline 24. & Availability of a telephone line & $\mathrm{x}$ & $\mathrm{x}$ \\
\hline 25. & Availability of a stereo & $\mathrm{x}$ & $\mathrm{x}$ \\
\hline
\end{tabular}

